\title{
TRAFFIC FLOW SIMULATION ON DISCRETE RATE APPROACH BASE
}

\author{
Mihails Savrasovs
}

Transport and Telecommunication Institute

Lomonosova str. 1, Riga, LV-1019, Latvia

Ph.:+37129654003.E-mail:mms@tsi.lv

The classical scientific literature dedicated to transport modelling has emphasised three levels of detail on which traffic models could be created. These levels are: microlevel, mesolevel and macroscopic level. Microscopic and macroscopic modelling are well known and widely used. The term 'mesoscopic modelling' has been interpreted by different scientists in different ways. In general, mesoscopic traffic flow models are understood to be models where traffic flow is described with a high level of detail, but at the same time flow behaviour and flow interactions are presented with a low level of description. The previously proposed new simulation approach (called 'mesoscopic simulation') was applied to traffic flow simulation. All the described models were implemented using Microsoft Excel and VBA. However, the practical application concerns that to construct more sophisticated models Microsoft Excel and VBA could not be used, because of programming complexity.

The main goal of this paper is to present examples of the application of the discrete rate approach of ExtendSim simulation software for traffic flow simulation. A literature survey has shown that the discrete rate approach is mainly used in logistics, but not in the area of transport area. So the tasks of this paper are to present the main techniques of model implementation using a discrete rate approach and to apply this approach to traffic flow simulation.

Keywords: Discrete rate, mesoscopic models, traffic flow

\section{Introduction}

Many new mathematical models for traffic systems have been developed. Almost all of them can be categorized as macroscopic or microscopic models. Macroscopic models [1] use differential equations and describe the behaviour of traffic flows. In such models long periods of time (days, hours) can be observed. Microscopic models use standard simulation models based, among other things, on discrete events [2] and cellular automats [3]. Models of this class are used to model short periods of time with a very high level of detail. In $[4,5]$ a new class of so called mesoscopic models has been described. The purpose of this model class is to take advantage of the two traditional approaches to modelling flow systems while avoiding their disadvantages such as the amount of time and labour involved in creating and implementing microscopic models.

The basic principles of mesoscopic modelling can be described as 'algorithmic management and analytical calculation' and 'discrete time and continuous quantities'. The second phrase shows that the philosophy of mesoscopic modelling has similarities with macroscopic modelling with differential equations. However, this analogy can only be observed in the presentation of numerical results. Results are presented as process graphs with the time step $\Delta t$. In mesoscopic models, relationships between variables are often implemented as complex algorithms and not as concrete formulas. This is a characteristic of microscopic simulation.

A mesoscopic model uses mathematical formulae to calculate the results as continuous quantities in every step $\Delta t$ of the discrete modelling time. In contrast to the microscopic approach, the mesoscopic approach monitors quantities of objects that belong to a logical group instead of individual flow objects (e.g. customers in queuing systems). In contrast to macroscopic models, any number of groups of objects can exist at the same time in mesoscopic models, and interactions between them can be implemented.

In [5] it has been shown that 'multichannel funnels' can be effectively used as the main structural component of mesoscopic models. The process of product accumulation and processing can be modelled with this component. Flow processing is done through different strategies of resource usage.

The advantages of the mesoscopic approach are the high degree of flexibility it allows in the preparation of input data for the simulation, the universal and simple structure of its internal model data, the fact that no restrictions for modelling complex control algorithms exist, its high level of performance for computing the model code and its clear presentation of simulation results. 
An example of using the mesoscopic approach for modelling a controlled crossroads is demonstrated in reference [6]. Reference [7] shows the validation of mesoscopic models on the basis of microscopic models. These references deal with using mesoscopic simulation to model a crossroads or a small group of crossroads. Unfortunately further investigation [7] shows that to model more complex transport objects such as transport corridors, Microsoft Excel with VBA cannot be used, due to issues of programming complexity. Research into possible alternatives to Microsoft Excel reveals that ExtendSim simulation software can be used. ExtendSim has a special library called 'Rate' approach. The description of this approach fully complies with the described mesoscopic approach to traffic simulation.

\section{Discrete-Rate Approach Comparison with Traditional Approaches}

The discrete rate approach is a new advanced simulation technology presented in 2009 by Imagine That, Inc. at the Winter Simulation Conference [8]. The mainly discrete rate approach is focused on logistics and manufacturing problems and used for material flow simulation. The difference between the traditional approaches (system dynamics, agent-based simulation and discrete event simulation) must be described. This description can be done on different levels.

\section{General comparison of approaches}

All the mentioned above simulation approaches (discrete rate, discrete event, system dynamics and agent-base simulation) could be separated into groups. The separation could be based on the level of detail. Discrete event simulation and agent-based simulation are mainly used at the microscopic level. The system dynamics approach can be applied at the macroscopic level. And finally, the discrete rate approach deals with the mesoscopic level. The figure below shows the relations between the levels from the point of view of input and output data.

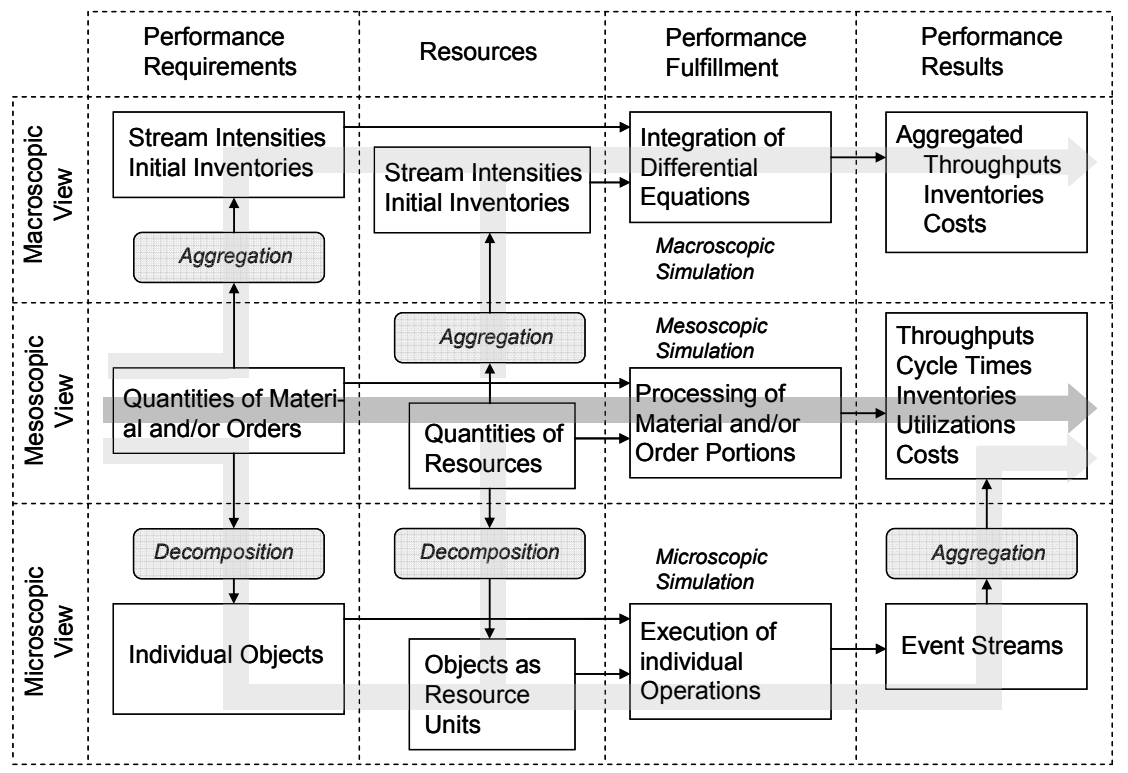

Figure 1. Relationships between levels

Figure 1 shows that application of macroscopic approaches is often connected with such operations as aggregation of data. This can explain why final results often are not very exact. The application of microscopic approaches is connected with decomposition operations. For this reason, model construction is a time-consuming process.

\section{Detailed comparison of approaches}

The following table shows a detailed comparison of the different approaches [9]. The first column is a comparison factor, the next 4 next columns present different approaches. The factors selected for comparison are: What is modelled; What causes a change in state; Time steps; Characteristics of what is modelled; Ordering; Routing; Statistical detail; Typical uses. 
Table 1. Comparison of simulation approaches

\begin{tabular}{|c|c|c|c|c|}
\hline Factor & System Dynamics & Discrete event & Discrete rate & Agent-based \\
\hline $\begin{array}{l}\text { What is } \\
\text { modelled }\end{array}$ & $\begin{array}{l}\text { Values that flow } \\
\text { through the model }\end{array}$ & $\begin{array}{l}\text { Distinct entities ('items' } \\
\text { or 'things') }\end{array}$ & $\begin{array}{l}\text { Bulk flows of } \\
\text { homogeneous } \\
\text { material, or flows of } \\
\text { otherwise distinct } \\
\text { entities where sorting } \\
\text { or separating is not } \\
\text { necessary }\end{array}$ & $\begin{array}{l}\text { Distinct active } \\
\text { entities }\end{array}$ \\
\hline $\begin{array}{l}\text { What causes a } \\
\text { change in state }\end{array}$ & A time change & An event & An event & $\begin{array}{l}\text { An event and } \\
\text { a time change }\end{array}$ \\
\hline Time steps & $\begin{array}{l}\text { Interval between } \\
\text { time steps is } \\
\text { constant. Model } \\
\text { recalculations are } \\
\text { sequential and time } \\
\text { dependent }\end{array}$ & $\begin{array}{l}\text { Interval between events } \\
\text { is dependent on when } \\
\text { events occur. Model only } \\
\text { recalculates when events } \\
\text { occur }\end{array}$ & $\begin{array}{l}\text { Interval between } \\
\text { events is dependent } \\
\text { on when events } \\
\text { occur. Model only } \\
\text { recalculates when } \\
\text { events occur }\end{array}$ & $\begin{array}{l}\text { In some models } \\
\text { the time step is } \\
\text { a constant and } \\
\text { could be defined } \\
\text { as very small } \\
\text { value. In some } \\
\text { models events } \\
\text { define the time } \\
\text { intervals }\end{array}$ \\
\hline $\begin{array}{l}\text { Characteristics } \\
\text { of what is } \\
\text { modelled }\end{array}$ & $\begin{array}{l}\text { Track } \\
\text { characteristics in a } \\
\text { database or assume } \\
\text { the flow is } \\
\text { homogeneous }\end{array}$ & $\begin{array}{l}\text { Using attributes, items } \\
\text { are assigned unique } \\
\text { characteristics and can } \\
\text { then be tracked } \\
\text { throughout the model }\end{array}$ & $\begin{array}{l}\text { Track characteristics } \\
\text { in a database or } \\
\text { assume the flow is } \\
\text { homogeneous }\end{array}$ & $\begin{array}{l}\text { Using attributes, } \\
\text { items are } \\
\text { assigned unique } \\
\text { characteristics } \\
\text { and behaviour }\end{array}$ \\
\hline Ordering & FIFO & $\begin{array}{l}\text { Items can move in FIFO, } \\
\text { LIFO, Priority, time- } \\
\text { delayed, or customized } \\
\text { order }\end{array}$ & FIFO & $\begin{array}{l}\text { Could be given } \\
\text { customized order } \\
\text { if necessary }\end{array}$ \\
\hline Routing & $\begin{array}{l}\text { Values need to be } \\
\text { explicitly routed by } \\
\text { being turned off at } \\
\text { one branch and } \\
\text { turned on at the } \\
\text { other (values can go } \\
\text { to multiple places at } \\
\text { the same time) }\end{array}$ & $\begin{array}{l}\text { By default, items are } \\
\text { automatically routed to } \\
\text { the first available branch } \\
\text { (items can only be in one } \\
\text { place at a time) }\end{array}$ & $\begin{array}{l}\text { Flow is routed based } \\
\text { on constraint rates } \\
\text { and rules that are } \\
\text { defined in the model } \\
\text { (flow can be divided } \\
\text { into multiple } \\
\text { branches) }\end{array}$ & $\begin{array}{l}\text { The routing is } \\
\text { done based on } \\
\text { agent behaviour }\end{array}$ \\
\hline Statistical detail & $\begin{array}{l}\text { General statistics } \\
\text { about the system: } \\
\text { amount, efficiency, } \\
\text { etc. }\end{array}$ & $\begin{array}{l}\text { In addition to general } \\
\text { statistics, each item can } \\
\text { be individually tracked: } \\
\text { count, utilization, cycle } \\
\text { time }\end{array}$ & $\begin{array}{l}\text { In addition to general } \\
\text { statistics, effective } \\
\text { rates, cumulative } \\
\text { amount }\end{array}$ & $\begin{array}{l}\text { Information about } \\
\text { each agent. } \\
\text { Average } \\
\text { characteristics } \\
\text { across all agents } \\
\text { or groups of } \\
\text { agents }\end{array}$ \\
\hline Typical uses & $\begin{array}{l}\text { Scientific (biology, } \\
\text { chemistry, physics), } \\
\text { engineering } \\
\text { (electronics, control } \\
\text { systems), finance } \\
\text { and economics, } \\
\text { System Dynamics } \\
\end{array}$ & $\begin{array}{l}\text { Manufacturing, service } \\
\text { industries, business } \\
\text { operations, networks, } \\
\text { systems engineering }\end{array}$ & $\begin{array}{l}\text { Manufacturing of } \\
\text { powders, fluids, and } \\
\text { high speed, high } \\
\text { volume processes. } \\
\text { Chemical processes, } \\
\text { ATM transactions. } \\
\text { Supply chains } \\
\end{array}$ & $\begin{array}{l}\text { Social processes, } \\
\text { biology, traffic } \\
\text { flows }\end{array}$ \\
\hline
\end{tabular}

As can be seen from Table 1, the discrete rate approach is very close to the system dynamics approach. The difference between them is hidden in the 'What causes a change in state' factor. In the case of system dynamics there is a predefined time change, in the case of the discrete rate, the events cause a change of the state of the system. A more detailed comparison of the system dynamics approach and the discrete rate approach can be found in [8].

\section{Discrete-Rate Library}

The discrete rate approach is presented in the ExtendSim library by 11 blocks, which can be used for model construction. As was mentioned before, the discrete rate approach is mostly used to simulate material flows. This is why each block can execute predefined operations with the flow. The following description can be given for each block [10]. 
Table 2. Rate library blocks

\begin{tabular}{|c|c|c|}
\hline Block & Block name & Description \\
\hline 0 & Bias & Prioritizes the flow going through it. \\
\hline Not connecter & Catch Flow & This block catches flow sent by Throw Blocks or Diverge blocks \\
\hline & Change unit & Changes the flow unit of measurement. \\
\hline 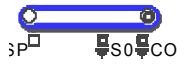 & Convey Flow & Delays the movement of flow from one point to another. \\
\hline & Diverge & Distributes the input flow to two or more outputs. \\
\hline \begin{tabular}{l|l} 
\\
$\mathrm{IC}$
\end{tabular} & Interchange & $\begin{array}{l}\text { The Interchange block represents a tank, or holding area, where flow } \\
\text { can interact with items generated by discrete event blocks. }\end{array}$ \\
\hline & Merge & Merges flows from multiple inputs into one output. \\
\hline $30 \quad \frac{10}{S R}$ & Sensor & $\begin{array}{l}\text { Reports the potential upstream supply rate and potential downstream } \\
\text { demand rate. }\end{array}$ \\
\hline $\mathrm{C}^{\mathrm{Q}}$ & Tank & $\begin{array}{l}\text { Acts as source, intermediate storage, or sink. As a residence type } \\
\text { block, the Tank has the capacity to hold defined amounts of flow as } \\
\text { time advances. }\end{array}$ \\
\hline Not connecter & Throw flow & $\begin{array}{l}\text { This block sends flow received by Catch Blocks or Merge blocks even } \\
\text { though the blocks. }\end{array}$ \\
\hline 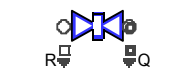 & Valve & Controls, monitors, and transfers flow. \\
\hline
\end{tabular}

As can be seen, some of blocks can be treated as the main blocks (Valve, Tank etc.) of the library, while some of the blocks are used as a helpers (at example Interchange). Of course blocks from other ExtendSim libraries could be used in the discrete rate models. To simulate transport flow, not all the described blocks are used. The following table could be constructed to show the main role of the blocks in a transport model (Table 3). As can be seen from Table 3, we need only 6 main blocks to construct a transport model. Of course additional ExtendSim blocks could be involved to collect and visualise output data.

Table 3. Main role of blocks in a transport model

\begin{tabular}{|c|c|l|}
\hline Block & Block name & Main role in transport model \\
\hline \multicolumn{1}{|c|}{ Convey Flow } & $\begin{array}{l}\text { Can be used to simulate a movement between two geographical points } \\
\text { (for example between two crossroads) }\end{array}$ \\
\hline & Diverge & $\begin{array}{l}\text { Can be used to simulate a splitting of the transport flow into different } \\
\text { direction (for example at a crossroads: turning left, turning right, } \\
\text { moving forward). }\end{array}$ \\
\hline & Sensor & $\begin{array}{l}\text { Can be used as the main source of information for controlling flows } \\
\text { and controlling flow interaction. }\end{array}$ \\
\hline
\end{tabular}




\section{Modelling and Source Data Description}

As the simulation object we have selected a transport corridor. A transport corridor is a (generally linear) tract of land in which at least one main line is provided for transport. This could be a road, rail or canal facility. In this paper, by 'transport corridor' we mean a road which connects two or more geographical points. The need for research and analysis into transport corridors is mainly connected with the wish to locate corridor bottlenecks estimate their different characteristics (for example, the average speed along the corridor, the average travel time etc). The main idea of a transport corridor can be represented in Figure 2.

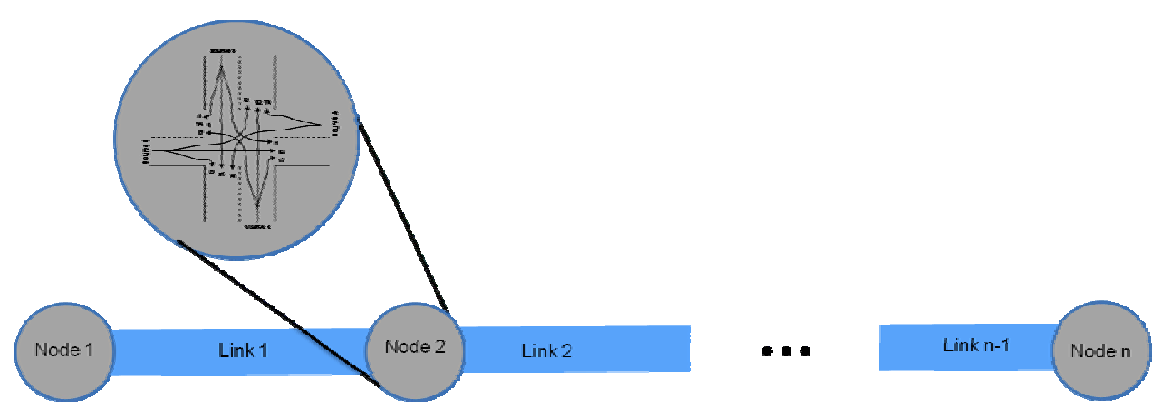

Figure 2. Schema of transport corridor

As can be seen, the structure of the transport corridor can be presented in node-link notation. The only thing which should be taken into account is a detailed simulation of the nodes. Let us assume for our example that we are going to model a transport corridor which consists of homogeneous symmetric crossroads. The number of crossroads is 3 . A detailed conceptual model could be constructed (Figure 3 ). Nodes 1 and 2 have 3 inputs as their sources of traffic, while node 2 has only 2 inputs of traffic. The length of the links is defined: link 1 length is $100 \mathrm{~m}$; link 2 length is $200 \mathrm{~m}$. The structure of the crossroads in each node is the same. All crossroads are controlled by traffic lights. In this example the cycle duration for all crossroads is 50 seconds $(20 s+5 s+20 s+5 s)$. All directions of movement are allowed. The two opposite sources have their green phase at the same time. During this time the two remaining sources have their red phase. This means that they do not interfere with each other. Transport flows are given and measured in PCUs (passenger car units). As we only want to demonstrate the general example of using a discrete rate approach for traffic flow simulation, the intensity of traffic input flow was chosen randomly.

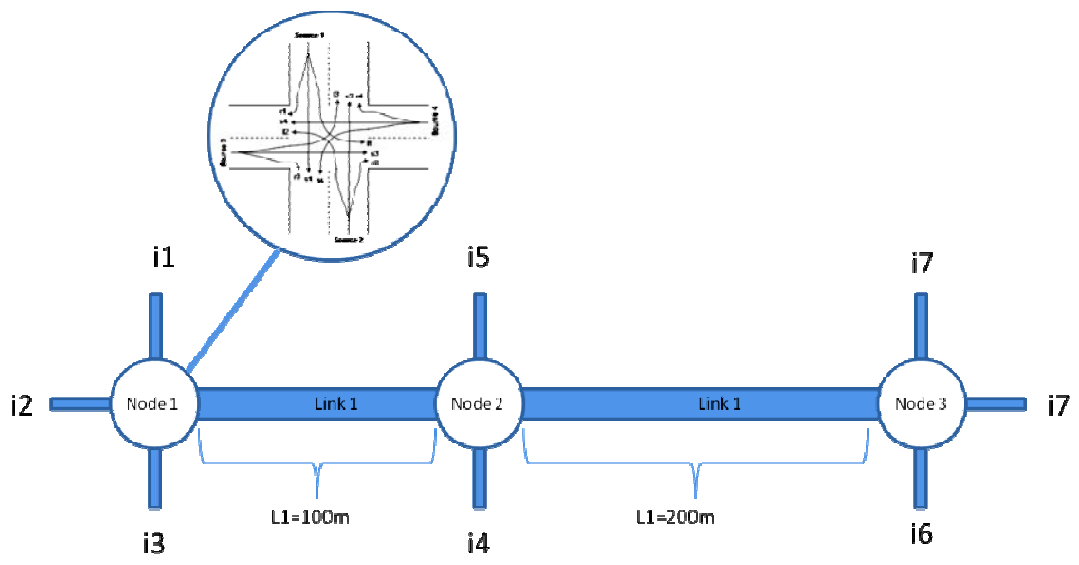

Figure 3. Simulation object

The simulation model was constructed using ExtendSim software. Because all crossroads have the same structure, the user defined object called Node was implemented. This object presents one crossroads. Using this object the following model was constructed (see Figure 4). 


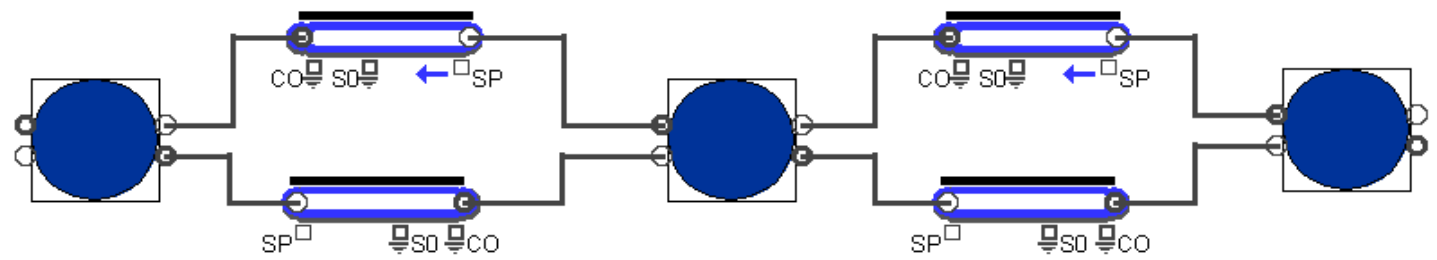

Figure 4. High level model constructed using ExtendSim

To connect Node objects to the transport corridors, a standard ExtendSim block Convey Flow was used. Each Convey Flow represents the direction and the opposite direction of the link. To connect a Convey Flow block with a Node block, 2 input and 2 output ports were implemented for the Node block. Each node block has almost the same structure; defined in terms of standard blocks. The figure below demonstrates a part of the Node block.

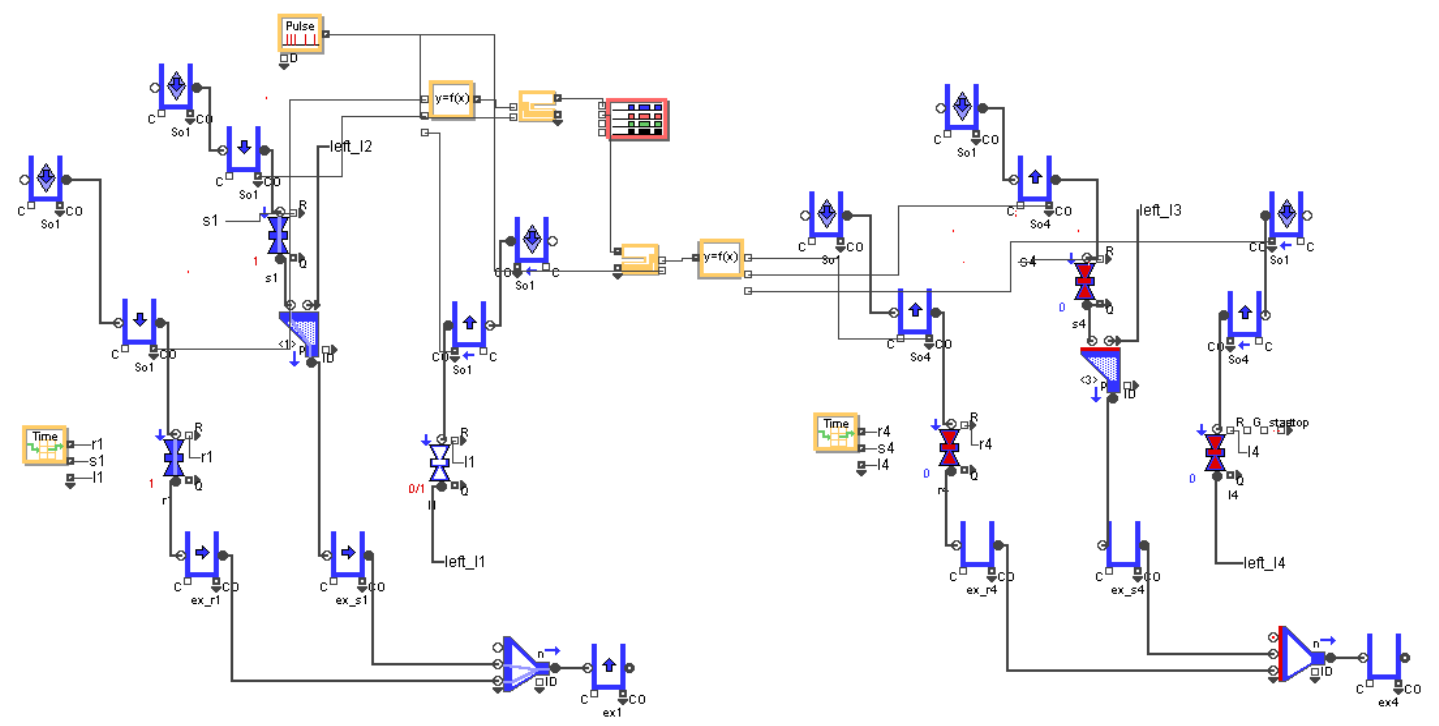

Figure 5. A part of the Node block

As can be seen for the Node object construction, only standard blocks from the Discrete-Rate library plus some additional blocks from other libraries were used.

The main output results of the simulation can be presented in the form of graphs which show different statistics such as:

- maximum queue length,

- average queue length,

- minimum queue length,

- maximum and average waiting time,

- the loading level of each crossroads in terms of crossroads utilisation.

\section{Conclusions}

- Because of the disadvantages of microscopic simulation and the disadvantages of macroscopic simulation, a new mesoscopic approach for traffic modelling is proposed in this article.

- Earlier attempts to demonstrate the potential of this new approach used Microsoft Excel and VBA. Unfortunately, owing to the large number of simulation objects, the complexity of the programming increased substantially. Therefore it was decided to use ExtendSim simulation software. A discrete rate approach realised with this software fully realised all the key components of mesoscopic simulation.

- The ExtendSim discrete rate library is proposed for material flow simulation. Consequently, this is mainly orientated towards logistics and production. 
- This article demonstrates how the discrete rate approach can be used to simulate transport corridors. The analysis of the block set of the library showed that only 6 of 11 blocks could be used for traffic flow simulation. These 6 blocks fully cover the required functionality needed to construct the model.

- A comparative analysis was conducted to show the differences between the discrete rate approach and classical approaches such as discrete events, system dynamics and agent-based simulations.

- Unfortunately, during the final analysis of the model, the following inaccuracies were found: the proposed model does not take into account that the running link length could become shorter because of growing queues before a crossroads; also, the growing queues do not influence the incoming flow (the incoming traffic flow can still pass the crossroads). These problems lead to inaccurate simulation results. Possible future research could examine how to bypass these disadvantages.

- This article demonstrates only a general approach towards using the Discrete-Rate approach, but the constructed model should be validated using existing models. This could also be the subject of future work.

\section{Acknowledgments}

The article is written with the financial assistance of the European Social Fund. Project Nr. 2009/0159/1DP/1.1.2.1.2/09/IPIA/VIAA/006 (The support in Realisation of the Doctoral Programme 'Telematics and Logistics'of the Transport and Telecommunication Institute).

\section{References}

1. Kühne, R. D., Rödiger, M. B. (1991). Macroscopic simulation model for freeway traffic with jams and stop-start waves. In Proceedings of the Winter Simulation Conference, 8-11 December (pp. 762-770). USA Phoenix, AZ: ACM Press.

2. Yatskiv, I., Yurshevich, E., Savrasov, M. (2007). Investigation of Riga Transport Node Capacity on the Basis of Microscopic Simulation, In Proceedings of the $21^{\text {st }}$ European Conference on Modelling and Simulation (ECMS 2007), Prague, Czech Republic, 4-6 June (pp. 584-589). Prague, Czech Republic: Curran Associates, Inc.

3. Esser, J., Schreckenberg, M. (1997). Microscopic simulation of urban traffic based on cellular automata. Int. J. Mod. Phys. C 8(5), 1025-1036.

4. Tolujew, J., Alcalá, F. (2004). A Mesoscopic Approach to Modelling and Simulation of Pedestrian Traffic Flows. In G. Horton (Ed.), Proceedings of the 18th European Simulation Multi-Conference, SCS International, Ghent, 13-16 June (pp. 123-128). Magdeburg, Germany: International SCS Publishing House.

5. Savrasov, M., Toluyew, Y. (2007). Application of Mesoscopic Modelling for Queuing Systems Research. In I. V. Kabashkin, I. V. Yatskiv (Eds.), Reliability and Statistics in Transportation and Communication (pp. 94-99). Riga: Transport and Telecommunication Institute.

6. Tolujew, J., Savrasov, M. (2008). Mesoscopic approach to modelling a traffic system. In Proceedings of the International Conference Modelling of Business, Industrial and Transport Systems, 7-10 May (pp. 147-151). Riga: Transport and Telecommunication Institute.

7. Savrasov, M., Toluyew, Y. (2008). Transport system's mesoscopic model validation using simulation on microlevel. In Proceedings of the $8^{\text {th }}$ International Conference, Reliability and Statistics in Transportation and Communication, 15-18 October (pp. 297-304). Riga, Latvia: Transport and Telecommunication Institute.

8. Krahl, David. (2009). ExendSim advanced technology: discrete rate simulation. In Proceedings of the 2009 Winter Simulation Conference, 13-16 December (pp. 333-338). Austin, TX, USA: WSC

9. Official webpage of ExtendSim, 04.04.2012 from www.extendsim.com

10. Imagine that, ExtendSim User Guide. Imagine that, 04.04.2012 from http://www.extendsim.com/support_manuals.html. ISBN: 978-0-9825040-0-0 